\title{
AÇOS INOXIDÁVEIS APLICADOS NA INDÚSTRIA PETROQUÍMICA: ESTUDO COMPARATIVO DA RESISTÊNCIA À CORROSÃO POR TÉCNICAS ELETROQUÍMICAS
}

\author{
Leonardo Augusto Luiz' \\ Sérgio Luiz Henke ${ }^{\prime}$ \\ Bruna Corina Emanuely Schibicheski Kurelo ${ }^{2}$ \\ Gelson Biscaia de Souza ${ }^{2}$ \\ Juliano de Andrade ${ }^{3}$ \\ Cláudia Eliana Bruno Marino ${ }^{\prime}$
}

\section{Resumo}

O objetivo deste estudo foi analisar comparativamente a resistência à corrosão dos aços inoxidáveis UNS S4I426 (martensítico), AISI 444 (ferrítico), UNS S3I 254 (austenítico) e UNS S32205 (duplex), em solução de $3,5 \% \mathrm{NaCl}$ por voltametria cíclica (VC) e espectroscopia de impedância eletroquímica (EIE). Os aços inoxidáveis duplex, austenítico e ferrítico se apresentaram estáveis e com valores elevados de resistência à polarização, enquanto o aço martensítico se apresentou suscetível a dissolução e repassivação em solução salina ao longo de 30 dias, conforme medidas de EIE e potencial de circuito aberto. $O$ aço duplex exibiu maior resistência à quebra do filme de passivação, seguido do austenítico, ferrítico e martensítico, além deste apresentar maior densidade de pites em sua superfície, o que foi revelado por microscopia eletrônica de varredura após medidas de VC. Esses resultados apontam que $\mathrm{Cr}$, Mo e $\mathrm{N}$ atuam de forma sinérgica na proteção, formação e repassivação do filme de óxido de cromo. Por fim, é ressaltada a importância dos aços inoxidáveis ferríticos e duplex, em que mesmo com menor teor de Ni é possível obter aços de resistência à corrosão superior ou equivalente aos tão comerciais austeníticos.

Palavras-chave: Aços inoxidáveis; Elementos de liga; Técnicas eletroquímicas; Resistência à corrosão.

\section{STAINLESS STEELS APPLIED IN THE PETROCHEMICAL INDUSTRY: A COMPARATIVE STUDY OF CORROSION RESISTANCE USING ELETROCHEMICAL TECHNIQUES}

\begin{abstract}
The objective of this study was to analyze comparatively the corrosion resistance of UNS S4I426 (martensitic), AISI 444 (ferritic), UNS S3 254 (austenitic) and UNS S32205 (duplex) stainless steel (SS) in NaCl 3.5 wt\%. The duplex, austenitic and ferritic SS showed a stable behaviour and high values of polarization resistance, while the martensitic SS was unstable in saline solution along 30 days of immersion, which was obtained by electrochemical impedance spectroscopy and open circuit potential. The duplex SS exhibited the more anodic passivity breakdown potential, followed by the austenitic, ferritic and more susceptible to corrosion, the martensitic SS, in addition presents a larger amount and size of pits, which was obtained by scanning electron microscopy after cyclic voltammetry. These data show that $\mathrm{Cr}$, Mo and $\mathrm{N}$ acts synergistically in the protection, formation and repassivation of the chromium oxide film. Lastly, the importance of duplex and ferritic stainless steel is emphasized, in which is possible to obtain steels with superior or equivalent corrosion resistance than the commercial austenitic, using lower Ni content.
\end{abstract}

Keywords: Stainless steel; Alloying elements; Electrochemical methods; Corrosion resistance.

'Departamento de Engenharia Mecânica, Universidade Federal do Paraná - UFPR, Curitiba, PR, Brasil. E-mail: leonardoal20I2@gmail.com ${ }^{2}$ Departamento de Física, Universidade Estadual de Ponta Grossa - UEPG, Ponta Grossa, PR, Brasil.

${ }^{3}$ Laboratório de Corrosão, Institutos Lactec, Curitiba, PR, Brasil.

2176-1523 (C) 2020 Associação Brasileira de Metalurgia, Materiais e Mineração. Publicado pela ABM. Este é um artigo de acesso aberto distribuído sob os termos da licença Creative Commons CC BY-NC-ND (Attribution-NonCommercial-NoDerivs) - https:// creativecommons.org/licenses/by-nc-nd/4.0\%. 


\section{INTRODUÇÃO}

Cerca de $20 \%$ da produção mundial de aço é perdida devido à corrosão, e além disso, aproximadamente $1 \%$ a $5 \%$ do produto interno bruto (PIB) dos países é utilizado com gastos provenientes de efeitos corrosivos [ $\mathrm{I}$ ]. Os equipamentos para aplicação na indústria petroquímica, em especial, estão sujeitos a diferentes formas de corrosão. Dentre os principais mecanismos, se tem a ação de íons cloreto provenientes da água do mar, corrosão sob tensão em equipamentos submetidos a cargas mecânicas, ação corrosiva de ácido sulfúrico e dióxido de carbono na extração do petróleo e corrosão microbiológica, devido a microrganismos existentes no oceano [2,3]. A combinação dos fatores mencionados e a importância econômica mundial apresentada por esta indústria, motivam o desenvolvimento de tecnologias que reduzam ou inibam a corrosão nesses meios altamente agressivos, assim como também o desenvolvimento de materiais com elevada resistência à corrosão, como os aços inoxidáveis [2,3]. Estas ligas $\mathrm{Fe}-\mathrm{Cr}$ e $\mathrm{Fe}-\mathrm{Cr}-\mathrm{Ni}$ possuem um mecanismo chamado de passivação, ou seja, a formação de um filme, na ordem de nanômetros, de óxido protetor na superfície do material, o qual confere propriedades de resistência à corrosão em diferentes meios. Isso se deve, principalmente, à presença do teor de $\mathrm{Cr}$ acima de 10,5\% em solução sólida, de forma que este sofre uma oxidação controlada, formando um filme passivo de óxido de cromo. Em soluções aquosas, o mecanismo de formação deste filme está ligado principalmente a desprotonação da água e de hidróxidos, como na Reação I, em que Mé um metal capaz de formar óxidos [4].

$$
\mathrm{mM}+\mathrm{n} / 2 \mathrm{H}_{2} \mathrm{O} \rightarrow \mathrm{M}_{\mathrm{m}} \mathrm{O}_{\mathrm{n} / 2}+\mathrm{nH}^{+}+\mathrm{ne}^{-}
$$

Além disso, os aços inoxidáveis podem ser separados em diferentes grupos, como: austeníticos, ferríticos, martensíticos, duplex e endurecidos por precipitação. Cada um destes grupos apresenta propriedades mecânicas e de resistência à corrosão únicas, devido às diferentes microestruturas e composições químicas apresentadas por estes materiais. Portanto, propriedades como resistência, crescimento, durabilidade e estabilidade do filme de óxido são influenciadas por outros elementos além do $\mathrm{Cr}$, como $\mathrm{Ni}, \mathrm{N}$ e Mo por exemplo [4]. Da mesma forma, a microestrutura e tamanho de grão podem influenciar na estabilidade do filme de $\mathrm{Cr}_{2} \mathrm{O}_{3}$ dos aços inoxidáveis $[5,6]$. A adição de Mo em aços inoxidáveis é comprovadamente benéfica, aumentando a estabilidade do filme passivo, porém, os mecanismos envolvidos ainda são tema de debate. Estudos apontam mecanismos em que o Mo auxilia no crescimento do filme através da desprotonação de hidróxidos, enriquecendo a interface metal/filme passivo com oxigênio e facilitando a formação de $\mathrm{Cr}_{2} \mathrm{O}_{3}$ [7]. Outro mecanismo proposto, é o impedimento da ação de íons agressivos pelo Mo através da formação de molibdatos, os quais atuam como uma barreira protetora e aumentando a estabilidade do óxido de cromo $[7,8]$. Por outro lado, a influência do $\mathrm{N}$ está relacionada aos mecanismos provenientes da formação de amônia e amônio, em que estes atuam como barreira físico-química à passagem de íons agressivos, mantendo a estabilidade do filme passivo. Além disso, estes dois compostos inibem a nucleação e crescimento de pites. $\mathrm{O}$ Mo e $\mathrm{N}$ ainda possuem mecanismos sinérgicos, em que a presença de amônia aumenta o pH da solução, promovendo a formação de molibdatos. Já a adição de Ni foi estudada em conjunto com a influência de outros elementos de liga, sendo encontrado em quantidades mínimas no filme passivo em seu estado metálico [7-9]. Elementos como manganês, enxofre e carbono, tendem a ter um efeito negativo na resistência à corrosão dos aços inoxidáveis, formando o sulfeto de manganês e carbonetos de cromo, os quais geram regiões preferenciais para nucleação de pites [4]. Para evitar a sensitização do aço inoxidável através da precipitação destes carbonetos, elementos estabilizadores como Ti, $\mathrm{W}, \mathrm{V}$ e $\mathrm{Nb}$ podem ser adicionados, visto que possuem maior afinidade química com o $\mathrm{C}$ quando comparado ao $\mathrm{Cr}$ [4]. Metalurgicamente, os elementos de liga possuem diferentes influências nos aços inoxidáveis, sendo separados em estabilizadores da ferrita ( $\mathrm{Cr}$, Mo, Si e Nb) e estabilizadores da austenita ( $\mathrm{Ni}, \mathrm{N}, \mathrm{C}$ e $\mathrm{Mn}$ ) [l0]. Assim, são agrupados em expressões em função de seu efeito ferritizante, denominado de cromo equivalente $\left(\mathrm{Cr}_{\mathrm{eq}}=\% \mathrm{Cr}+\% \mathrm{Mo}+1,5 \% \mathrm{Si}+0,5 \% \mathrm{NH}\right)$ e austenitizante, denominado de níquel equivalente $\left(\mathrm{Ni}_{\mathrm{eq}}=\% \mathrm{Ni}+0,5 \% \mathrm{Mn}+30(\% \mathrm{C}+\% \mathrm{~N})\right)$. Desta forma, são elementos de liga de elevada importância para obtenção da microestrutura adequada durante a produção de aços inoxidáveis austeníticos, ferríticos e duplex $[4,10,11]$. Teores excessivos de $\mathrm{Cr}$ e Mo podem ainda levar a precipitação de fases deletérias como $\sigma$ e $\chi$, dando origem a regiões susceptíveis à corrosão localizada. Isto se torna mais crítico em peças soldadas e tratadas termicamente, pois podem promover a segregação do $\mathrm{Cr}$ e Mo, facilitando a formação destas fases prejudiciais a resistência mecânica e à corrosão dos aços inoxidáveis $[4, \mathrm{I} \mathrm{I}]$. O teor de níquel pode ainda melhorar a tenacidade e a resistência à quente dos aços inoxidáveis, enquanto o $\mathrm{N}$ retarda a formação da fase $\sigma$. Já elementos como alumínio e silício podem levar a formação de um segundo filme passivo nos aços inoxidáveis, constituído por $\mathrm{Al}_{2} \mathrm{O}_{3}$ ou $\mathrm{SiO}_{2}$, principalmente em condições de oxidação em elevada temperatura [ 12,13$]$. Além dos elementos de liga, estudos recentes encontraram evidências de interação galvânica entre a fase $\alpha$ e $\gamma$ de aços inoxidáveis duplex, que potencializam o efeito dos elementos de liga na formação do óxido de cromo $[9,14]$. Na literatura, é possível encontrar diversas publicações abordando a resistência à corrosão de diferentes aços inoxidáveis. Entretanto, estes estudos tendem a analisar um único material durante períodos curtos de imersão (Ih a 2 dias). Visto que na indústria petroquímica diferentes aços inoxidáveis são utilizados, e a durabilidade dos componentes é de extrema 
importância, existe a necessidade de se compreender como estes materiais se comportam por longos períodos de exposição em um meio corrosivo. Assim, este trabalho tem como objetivo a análise da resistência à corrosão de quatro ligas de aços inoxidáveis, as quais são aplicadas em componentes do processamento e extração do petróleo, sendo avaliadas de forma precisa pela técnica de espectroscopia de impedância eletroquímica ao longo de 30 dias de imersão em $3,5 \% \mathrm{NaCl}$. Além disso, as propriedades eletroquímicas são discutidas em função da composição química e fases destas ligas.

\section{MATERIAIS E MÉTODOS}

Foram estudados quatro tipos de aços inoxidáveis: martensítico (UNS S4I426), ferrítico (AISI 444), austenítico (UNS S3I254) e duplex (UNS S32205). A composição química destes aços, obtida por um analisador de fluorescência de raios $X(F R X)$ portátil da marca Oxford Instruments modelo X-Met 7000, é apresentada na Tabela I. A técnica de $F R X$ permite obter com precisão de até $0,01 \%$ o teor de elementos com massa atômica superior à do flúor. Com isso, os teores de nitrogênio dos aços duplex e austenítico, estão em torno de $0,2 \%$ de acordo com a norma ASTM A 240/A 240M. Já os demais elementos se encontram dentro da faixa requerida pela norma.

A caracterização das microestruturas e fases cristalinas foi feita por metalografia e difração de raios $X(D R X)$. As amostras foram lixadas partindo de uma granulometria de 420 até 1500 mesh e em seguida polidas em alumina $3 \mu \mathrm{m}$, até a condição especular. $\mathrm{O}$ ataque químico destes materiais para $\circ$ ensaio metalográfico foi realizado com os seguintes reativos: reagente de Marble $\left(4 \mathrm{~g} \mathrm{CuSO}_{4}+20 \mathrm{ml} \mathrm{HCl}+20 \mathrm{ml} \mathrm{H}_{2} \mathrm{O}\right)$ para o aço martensítico, para os aços ferrítico e duplex, um ataque eletroquímico em solução de $10 \mathrm{~g}$ de ácido oxálico $+100 \mathrm{ml} \mathrm{H}_{2} \mathrm{O}$, sob potencial de $3 \mathrm{~V}$ durante 30 segundos. Por fim o aço austenítico teve sua microestrutura revelada em um ataque por imersão em solução de $100 \mathrm{ml} \mathrm{HCl}+100 \mathrm{ml} \mathrm{H}_{2} \mathrm{O}$. Foi utilizado um microscópio óptico Olympus BX5 IM para metalografia e para ensaio de DRX um difratômetro Shimadzu XRD-6000. Com o intuito de se analisar a corrosão em um ambiente agressivo e representativo à indústria petroquímica, os ensaios eletroquímicos foram realizados em solução de $3,5 \% \mathrm{NaCl}$. A estabilidade eletroquímica, assim como a caracterização da interface metal/solução ao longo do tempo, foi obtida por medidas de potencial de circuito aberto (ECA) em conjunto com espectroscopia de impedância eletroquímica (EIE). Estas medidas foram analisadas em tempos de imersão de I h, $4 \mathrm{~h}, \mathrm{I}$ dia, 2 dias, 7 dias, 15 dias e 30 dias, e em uma faixa de frequência de $10^{5}$ a $10^{-2} \mathrm{~Hz}$, com potencial de perturbação senoidal $A C$ de $10 \mathrm{mV}$ e potencial $D C$ sendo o ECA.

$A$ análise da reatividade das superfícies dos aços inoxidáveis foi realizada por meio dos valores de potencial de pite $\left(E_{p}\right)$ e potencial de repassivação $\left(E_{R}\right)$, obtidos por medidas de voltametria cíclica (VC). As voltametrias iniciaram $\left(E_{1}\right)$ em $-500 \mathrm{mV}$ vs ECS e o potencial foi variado no sentido anódico até que a densidade de corrente atingisse $10 \mathrm{~mA} \cdot \mathrm{cm}^{-2}$, para a primeira análise, e até $1500 \mathrm{mV}$ vs ECS para a segunda análise, sendo feita então uma varredura catódica até um potencial final $\left(\mathrm{E}_{\mathrm{F}}\right)$ igual ao $\mathrm{E}_{\text {l. }}$. Todos os perfis voltamétricos foram obtidos com uma taxa de varredura de $5 \mathrm{mV} / \mathrm{s}$, onde estas condições foram otimizadas e empregadas nesta pesquisa a fim de assegurar a resposta anódica do sistema eletroquímico. A primeira análise foi realizada com $\circ$ intuito de obter $\circ E_{p}$ e em seguida visualizar os efeitos corrosivos pela análise da morfologia superficial, com auxílio de um microscópio eletrônico Tescan Vega3 LMU. A segunda análise foi feita com o intuito de submeter os aços inoxidáveis a condições severas de corrosão e assim, analisar a capacidade de repassivação através do $E_{R}$. Além disso, foi calculado o valor do Pitting equivalent Number (PREn). Este parâmetro está correlacionado a resistência à corrosão por pites dos aços inoxidáveis, e é obtido em função da concentração dos principais elementos de sua composição química que auxiliam na resistência à corrosão $(\mathrm{Cr}, \mathrm{Mo} \mathrm{e} \mathrm{N})[8,15]$. Dentre as diversas equações para calcular esta variável, umas das mais utilizadas e aplicada nos cálculos deste trabalho é a PREn $=[\mathrm{Cr}]+3.3[\mathrm{Mo}]+16[\mathrm{~N}]$. Para todos estes ensaios eletroquímicos, as amostras foram lixadas antes da imersão em solução contendo íons cloreto, partindo de uma granulometria de 420 até 1500 mesh e posteriormente limpas em água destilada. Foi utilizada uma célula eletroquímica padrão com três eletrodos, onde o eletrodo de referência utilizado foi o de calomelano saturado ( $\mathrm{ECS}-\mathrm{Hg}, \mathrm{H}_{2} \mathrm{Cl}_{2}, \mathrm{KCl}_{\mathrm{sat}}$ ), ○ contra eletrodo sendo uma espiral de platina e o eletrodo de trabalho, com uma área útil de $0,265 \mathrm{~cm}^{2}$, foram os aços inoxidáveis. O equipamento utilizado para todos os ensaios eletroquímicos foi um potenciostato-galvanostato da marca Gamry modelo Reference 3000.

Tabela I. Composição química obtida por FRX dos aços martensítico (UNS S4 I426), ferrítico (AISI 444), austenítico (UNS S3 I 254) e duplex (UNS S32205)

\begin{tabular}{|c|c|c|c|c|c|c|c|c|}
\hline Aço & $\% \mathrm{Cr}$ & $\%$ Mo & $\% \mathbf{N i}$ & $\% M n$ & $\% \mathrm{Cu}$ & $\% W$ & $\% \mathbf{N b}$ & $\% \mathrm{Fe}$ \\
\hline UNS S4 I 426 & 11,8 & 2,1 & 5,8 & 0,5 & 0,1 & - & 0,1 & Bal. \\
\hline AISI 444 & 17,8 & 2,5 & 0,3 & 0,3 & 0,1 & 0,1 & 0,2 & Bal. \\
\hline UNS S3 I 254 & 18,6 & 6,9 & 17,9 & 0,5 & 0,7 & - & - & Bal. \\
\hline UNS S32205 & 22,5 & 3,4 & 5,3 & 1,6 & 0,2 & - & - & Bal. \\
\hline Erro (\%) & & & & & & & & 0,01 \\
\hline
\end{tabular}




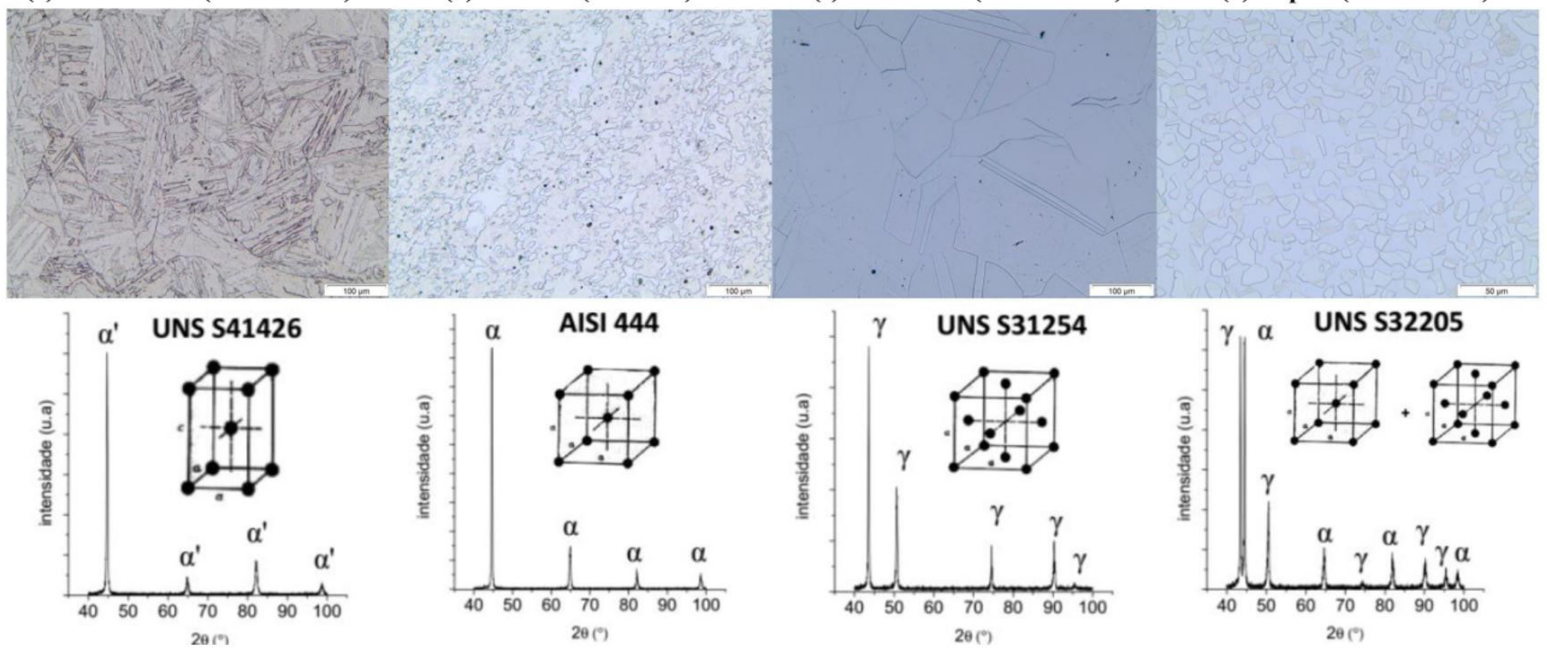

Figura I. Microestruturas e estruturas cristalinas obtidas por metalografia e DRX para os aços martensítico (UNS S4 I 426) (a), ferrítico (AISI 444) (b), austenítico (UNS S3I254) (c) e duplex (UNS S32205) (d).

\section{RESULTADOS E DISCUSSÃO}

\section{I Caracterização Microestrutural e Cristalográfica}

As microestruturas e estruturas cristalinas obtidas por metalografia e DRX são apresentadas na Figura I. $\mathrm{O}$ aço UNS S4I426, Figura Ia, possui uma microestrutura martensítica no seu estado temperado, caracterizada por seu formato acicular. No entanto, os ângulos detectados no difratograma indicam uma estrutura cúbica de corpo centrada (CCC) ao invés de uma estrutura tetragonal de corpo centrada (TCC). Isto se deve ao baixo teor de $C(0,03 \% \leq)$ que este aço inoxidável possui, de forma que não há uma grande distorção da rede cristalina por supersaturação de carbono, ou seja, se trata de uma martensita de baixo carbono, que confere elevada rigidez e baixa tenacidade a este aço $[4,16]$. Os contornos de macla, Figura Ic, caracterizam a fase $\gamma$ do aço UNS S3 1254. A microestrutura é confirmada pelos picos em ângulos típicos de uma estrutura cúbica de face centrada (CFC). A presença de nitretos é comum na microestrutura ferrítica $(\alpha)$ do aço AISI 444, Figura Ib, pois como é confirmado pela estrutura CCC obtida por DRX, este material é susceptível à fragilização por elementos intersticiais, de forma que é necessária a adição de elementos estabilizadores ( $\mathrm{W}, \mathrm{Ti}, \mathrm{Nb}$ e $\mathrm{V}$ ) para evitar este efeito [4]. Por fim, o aço inoxidável duplex, Figura Id, é caracterizado por sua microestrutura bifásica formada por ilhas de fase $\gamma$ e uma matriz $\alpha$, assim como também pelos picos correlacionados a estruturas CFC e CCC. Devido a esta microestrutura bifásica, os aços inoxidáveis duplex possuem uma sinergia entre as propriedades mecânicas e de corrosão dos austeníticos e ferríticos, como a resistência à corrosão sob tensão dos ferríticos em conjunto com a elevada tenacidade e estabilidade eletroquímica dos austeníticos $[4,16]$.

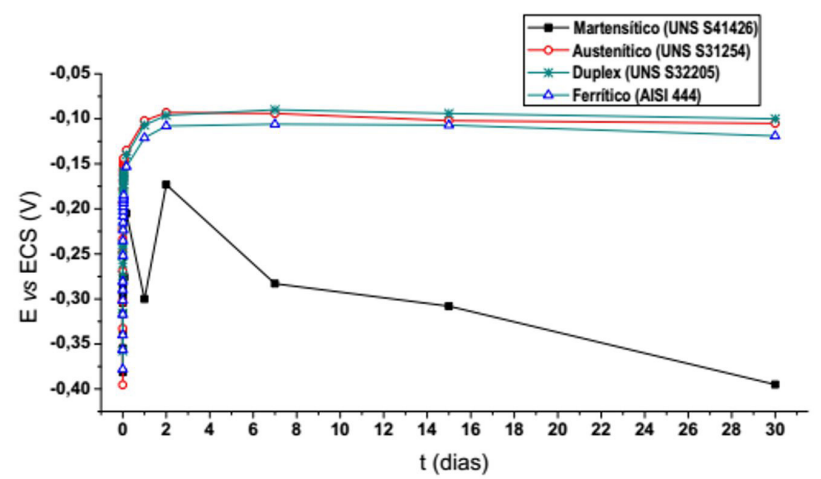

Figura 2. Potencial de circuito aberto em função do tempo dos aços martensítico (UNS S4I426), ferrítico (AISI 444), austenítico (UNS S3 I 254) e duplex (UNS S32205).

\subsection{Estabilidade Eletroquimica: por ECA e EIE}

Com o objetivo de se avaliar a estabilidade dos aços inoxidáveis e analisar a susceptibilidade à corrosão/dissolução, foi realizado o ensaio de ECA, em que os dados são apresentados, para 30 dias de imersão em solução de $3,5 \%$ $\mathrm{NaCl}$, na Figura 2. Inicialmente, nota-se que os aços ferrítico, austenítico e duplex apresentam potenciais mais nobres do que aço martensítico. Além disso, estes três materiais atingirem, ao fim de 30 dias de imersão em solução salina, potenciais mais positivos $(\cong-0,100 \mathrm{~V})$ do que em Ih, sendo consideravelmente estáveis. Já o aço martensítico apresentou uma superfície muito ativa, com oscilações do ECA e tendendo a potenciais mais negativos ao fim de 30 dias de imersão $(-0,395 \mathrm{~V})$ ou seja, apresenta instabilidade da interface metal/ solução podendo estar susceptível à dissolução do filme de $\mathrm{Cr}_{2} \mathrm{O}_{3}$ em meio contendo íon cloreto.

A fim de se caracterizar a interface metal/solução e analisar a estabilidade eletroquímica do sistema através de parâmetros elétricos, como a resistência à polarização $\left(R_{p}\right)$, 
foram realizadas medidas de impedância eletroquímica. Os espectros de Nyquist e Bode dos respectivos aços inoxidáveis são apresentados na Figura 3a-d.

Os aços duplex, austenítico e ferrítico apresentam um filme estável de óxido, o que pode ser visto pela sobreposição das curvas no espectro $\log |\mathrm{Z}|$ vs $\log \mathrm{f}$ ao longo do tempo de imersão em solução salina, Figura 3. Pela análise do espectro $-\theta$ vs log $\mathrm{f}$, estes materiais possuem uma grande faixa de frequências $\left(10^{2} \mathrm{a} 10^{-2} \mathrm{~Hz}\right)$ em que o ângulo de fase se encontra próximo de $-90^{\circ}$, ou seja, apresentam um comportamento capacitivo com mínima transferência de carga, característico de um filme passivo do tipo barreira. A presença de apenas um máximo de ângulo de fase no espectro - $\theta$ vs $\log$ f, uma reta no espectro do $\log |Z|$ vs $\log$ fe um semicírculo no espectro de Nyquist leva a inferência de que os aços ferrítico e duplex apresentam apenas um fenômeno capacitivo em sua interface, sendo atribuído à capacitância do filme passivo. No entanto, o aço austenítico possui, após 30 dias de imersão em solução salina, um segundo máximo do ângulo de fase, localizado em ângulos com indicação de comportamento menos capacitivo $\left(\cong-62^{\circ}\right)$ no domínio de baixas frequências. Além disso, é possível observar a formação de um segundo semicírculo no espectro de Nyquist, o que pode ser visualizado na análise dos espectros na Figura 4.

Isto pode estar correlacionado a fenômenos de transferência de carga devido dissolução do óxido de ferro na região mais externa do filme. Diversos autores descrevem o filme passivo de aços inoxidáveis como uma bicamada, sendo a camada interna rica em óxido de cromo, com características de semicondutor do tipo $\mathrm{p}$, e a externa rica em óxido de ferro com característica de semicondutor tipo n $[17,18]$. Considerando esta hipótese, após 30 dias exposto em solução corrosiva, é possível que a região externa do filme passivo do aço inoxidável austenítico (a) UNS S41426 Martensítico
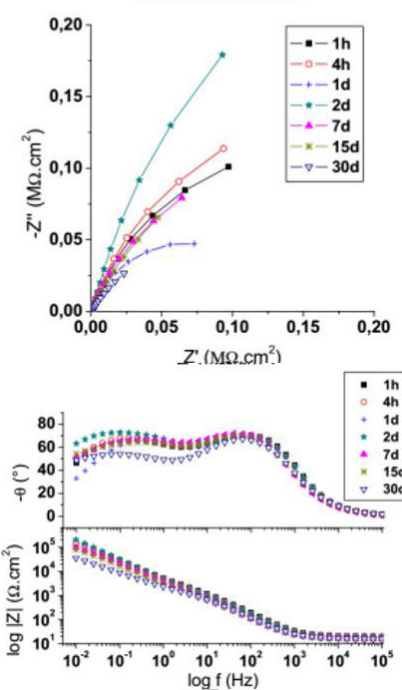

(b) UNS S31254 Austenítico
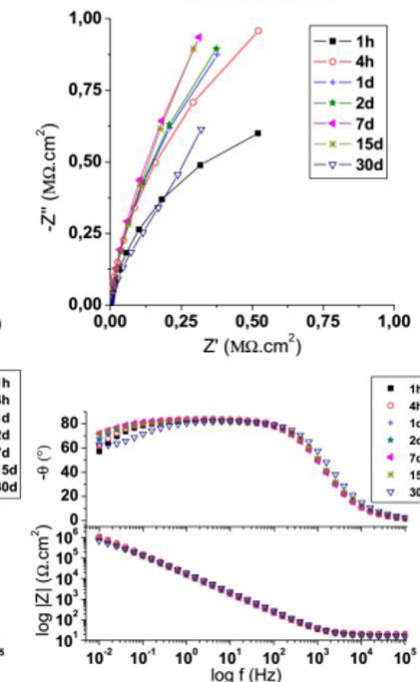

(c) AISI 444 Ferrítico
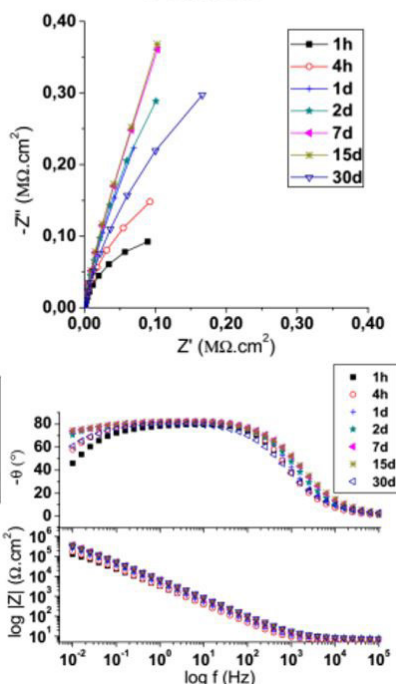

(d) UNS S32205

Duplex
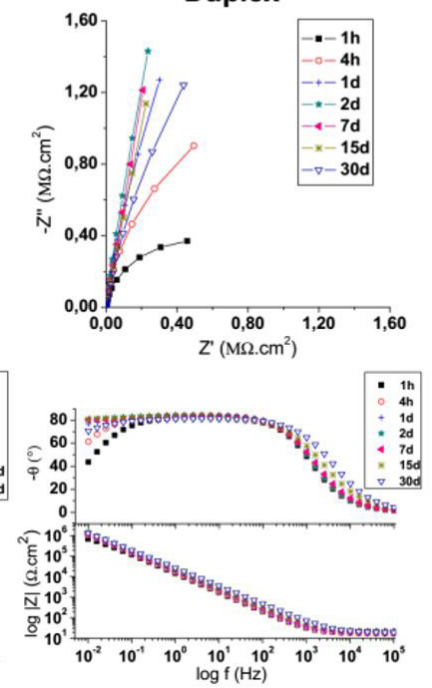

Figura 3. Espectros de Nyquist e Bode para o aço martensítico (UNS S4I246) (d), ferrítico, (AISI 444) (c), austenítico (UNS S3 I 254) (a) e duplex (UNS S32205) (b) na faixa de frequência de $10^{5} \mathrm{a} 10^{-2} \mathrm{~Hz}$, no potencial DC de circuito aberto com perturbação senoidal de $10 \mathrm{mV}$, em solução de $3,5 \% \mathrm{NaCl}$.
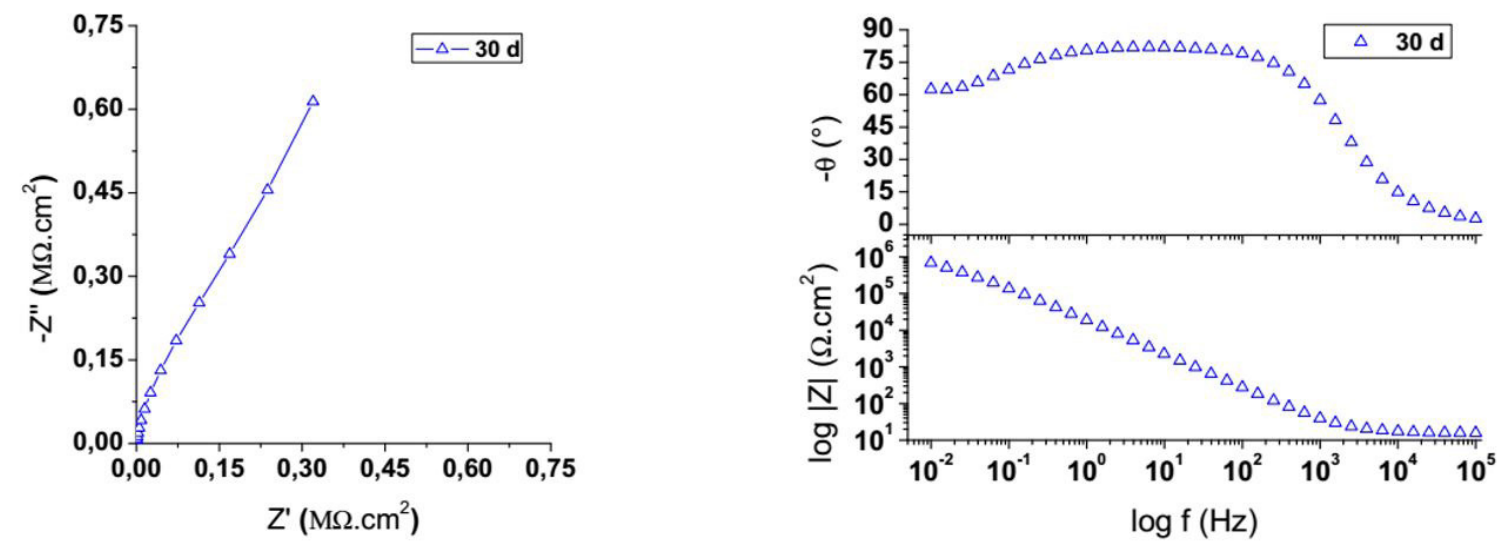

Figura 4. Espectros de Nyquist e Bode para o aço austenítico (UNS S3 I 254) na faixa de frequência de $10^{5}$ a $10^{-2} \mathrm{~Hz}$, no potencial DC de circuito aberto com perturbação senoidal de $10 \mathrm{mV}$, após 30 dias de imersão em solução de $3,5 \% \mathrm{NaCl}$. 
seja formada majoritariamente por óxido de ferro, além de possuir defeitos devido a fácil dissolução deste óxido, como é apresentado no esquema da Figura 5.

Enquanto os aços inoxidáveis ferrítico, austenítico e duplex possuíam um comportamento estável da interface metal/solução, o aço martensítico se apresentou instável ao longo do tempo. Isto é analisado, além da oscilação do ECA deste material, pela oscilação do módulo da impedância ( $\log |Z|$ vs $\log f$ ) e dos diâmetros dos semicírculos no espectro de Nyquist ao longo dos 30 dias de imersão, sugerindo processos de dissolução e repassivação, Figura $3 a$. Ademais, há a presença de dois máximos do ângulo de fase no espectro $-\theta$ vs $\log f$. A partir do estudo realizado por Marcelin et al. utilizando um aço inoxidável martensítico, a constante de tempo no domínio de altas frequências pode ser associado a capacitância do filme passivo, enquanto que a localizada no domínio de baixas frequências, pode ser atribuída aos processos de transferência de carga correlacionados a oxidação do substrato e redução do oxigênio [19]. As análises realizadas pelos espectros de impedância permitem a escolha de circuitos elétricos equivalentes (CEQ) que representem os sistemas eletroquímicos em estudo. Através destes, é possível obter parâmetros elétricos que permitem interpretações mais representativas da interface metal/solução e dos processos cinéticos que nesta região ocorrem. Os CEQ utilizados para caracterizar a interface metal solução são apresentados na Figura 6.

Os elementos RI e R2/CPE I estão correlacionados, respectivamente, para todos os circuitos como a resistência do eletrólito, resistência do filme passivo e a capacitância do filme passivo por um elemento de fase constante, considerando o desvio da idealidade de um capacitor puro. A impedância de um CPE pode ser calculada pela seguinte Equação 2:

$$
\hat{Z}=\left[\frac{\cos (n \pi / 2)}{Y \omega^{n}}\right]-j\left[\frac{\sin (n \pi / 2)}{Y \omega^{n}}\right]
$$

em que $\mathrm{n}$ é o fator de fase constante $(0 \leq \mathrm{n} \leq 1), Y$ está correlacionado com a capacitância do $\mathrm{CPE}$, $\omega$ é a frequência angular e $j$ é a unidade imaginária do vetor complexo da impedância. Quando o fator $n$ é tal que $n=I$, o CPE representa um capacitor puro, para $n=0$ representa um resistor puro e para $n=0,5$; uma impedância de Warburg relacionada com fenômenos difusionais. Os elementos R3/CPE2, para o aço martensítico, Figura 6a, representam a resistência à transferência de cargas e a capacitância da dupla camada elétrica. Para o aço austenítico, Figura $6 \mathrm{c}$, $\mathrm{R} 3 / \mathrm{CPE} 2$ representam a resistência e capacitância da região externa do filme rica em $\mathrm{Fe}_{2} \mathrm{O}_{3}$, após 30 dias de imersão em solução salina. Todos os circuitos aqui apresentados já foram sugeridos por outros autores na caracterização de alguns aços inoxidáveis em meios contendo íons cloretos e outras soluções $[5,6,8,9,19]$. Os valores dos elementos elétricos foram obtidos pelo fitting utilizando o software Zview e são apresentados na Tabela 2.

Os valores de $\mathrm{Y}$ do CPEI destes aços inoxidáveis podem ser aproximados para um valor de capacitância do filme, visto que os valores de $n$ estão muito próximos de I, ou seja, de um capacitor puro. Analogamente a um capacitor, a capacitância pode variar em função da distância entre as placas (análoga a espessura do filme) $[5,8,19]$. Outra variável (a)

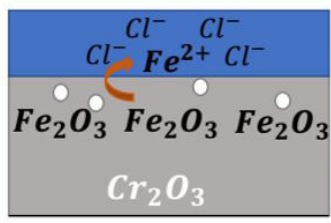

Substrato (b)

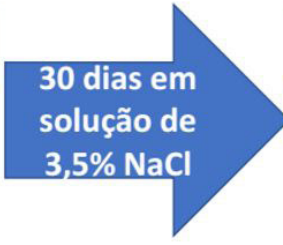

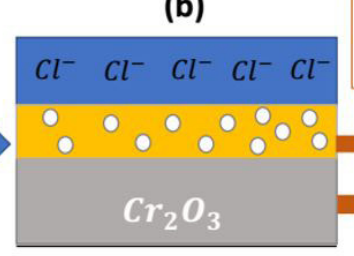

Substrato
Região externa com defeitos

devido dissolução do $\mathrm{Fe}_{2} \mathrm{O}_{3}$

Figura 5. Dissolução do óxido de ferro ao longo do tempo na região mais externa do filme passivo do aço austenítico (UNS S3I254) (a), gerando, após 30 dias de imersão, uma estrutura de bicamada, sendo a região externa rica em $\mathrm{Fe}_{2} \mathrm{O}_{3}$ e a região interna rica em $\mathrm{Cr}_{2} \mathrm{O}_{3}(\mathrm{~b})$.

(a)

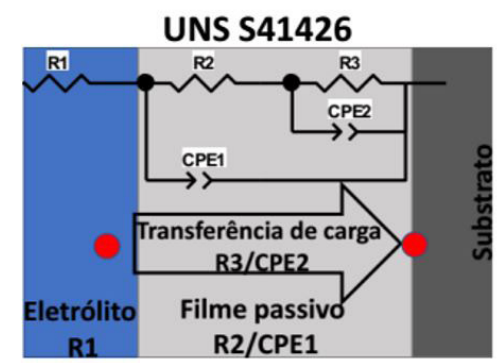

(b) UNS S32205, AISI 444 e UNS $\$ 31254$ (1h a 15 dias)

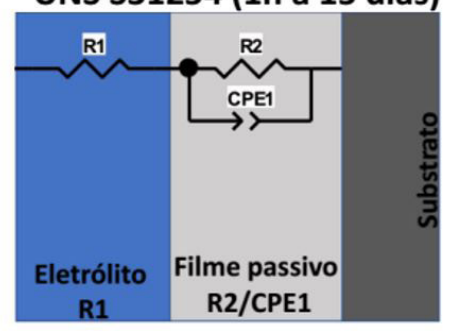

(c)

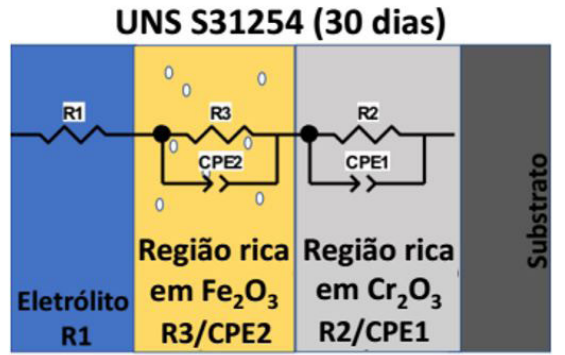

Figura 6. Circuitos elétricos equivalentes utilizados para caracterizar a interface metal/solução dos aços inoxidáveis UNS S4I426 (a), AISI 444 (b), UNS S32205 (b), UNS S3I 254 na faixa de Ih a I5 dias (b) e em 30 dias (c) de imersão em solução de $3,5 \% \mathrm{NaCl}$. 
Tabela 2. Valores obtidos para o fitting dos componentes do circuito apresentado na Figure 5a-c, para os aços martensítico (UNS 4I426), austenítico (UNS S3 I 254), ferrítico (AISI 444) e duplex (UNS S32205)

\begin{tabular}{|c|c|c|c|c|c|c|c|c|}
\hline \multirow[b]{2}{*}{$\mathbf{T}$} & \multirow{2}{*}{$R_{1}\left(\Omega . c m^{2}\right)$} & \multirow{2}{*}{$R_{2}\left(\Omega . \mathrm{cm}^{2}\right)$} & \multicolumn{2}{|c|}{ CPEI } & \multirow{2}{*}{$R_{3}\left(\Omega . \mathrm{cm}^{2}\right)$} & \multicolumn{2}{|c|}{ CPE2 } & \multirow[b]{2}{*}{$x^{2}$} \\
\hline & & & $\boldsymbol{Y}\left(\boldsymbol{\mu} \boldsymbol{F} . \mathrm{cm}^{-2}\right)$ & $\mathbf{n}$ & & $Y\left(\mu F . \mathrm{cm}^{-2}\right)$ & $\mathbf{n}$ & \\
\hline \multicolumn{9}{|c|}{ Martensítico UNS S4 | 426} \\
\hline $\mathrm{I} \mathrm{h}$ & 19,95 & $3,1 \times 10^{3}$ & $|8,8|$ & 0,880 & $3,0 \times 10^{5}$ & 32,07 & 0,767 & $2,3 \times 10$ \\
\hline $4 \mathrm{~h}$ & 18,89 & $3,0 \times 10^{3}$ & 22,06 & 0,873 & $3,4 \times 10^{5}$ & 32,51 & 0,786 & $1,7 \times 10$ \\
\hline I dia & 16,98 & $2,3 \times 10^{3}$ & 22,63 & 0,878 & $1,3 \times 10^{5}$ & 38,83 & 0,769 & $1,7 \times 10^{-}$ \\
\hline 2 dias & 18,76 & $2,9 \times 10^{3}$ & 20,95 & 0,819 & $9,5 \times 10^{5}$ & 26,28 & 0,819 & $1,3 \times 10$ \\
\hline 7 dias & 16,14 & $2,6 \times 10^{3}$ & 31,30 & 0,882 & $2,8 \times 10^{5}$ & 39,99 & 0,717 & $5,0 \times 10$ \\
\hline 15 dias & 15,69 & $2,2 \times 10^{3}$ & 39,50 & 0,860 & $3,2 \times 10^{5}$ & 51,23 & 0,690 & $6,4 \times 10^{-}$ \\
\hline 30 dias & 15,67 & $1,7 \times 10^{3}$ & 36,99 & 0,849 & $1,5 \times 10^{5}$ & 133,42 & 0,653 & $3,1 \times 10$ \\
\hline \multicolumn{9}{|c|}{ Austenítico UNS S3 I 254} \\
\hline $\mathrm{I} \mathrm{h}$ & 19,53 & $2,1 \times 10^{6}$ & 10,76 & 0,922 & - & - & - & $9,0 \times 10$ \\
\hline $4 \mathrm{~h}$ & 19,70 & $2,8 \times 10^{6}$ & 10,17 & 0,929 & - & - & - & $1,1 \times 10^{-}$ \\
\hline I dia & 18,12 & $3,3 \times 10^{6}$ & 12,25 & 0,919 & - & - & - & $1,2 \times 10^{-}$ \\
\hline 2 dias & 18,08 & $3,5 \times 10^{6}$ & 12,05 & 0,921 & - & - & - & $1,3 \times 10$ \\
\hline 7 dias & 18,78 & $4,7 \times 10^{6}$ & 12,07 & 0,920 & - & - & - & $1,8 \times 10$ \\
\hline 15 dias & 17,50 & $4,5 \times 10^{6}$ & 12,20 & 0,915 & - & - & - & $1,9 \times 10$ \\
\hline 30 dias & 16,08 & $3,4 \times 10^{6}$ & 16,35 & 0,978 & $2,3 \times 10^{5}$ & 10,88 & 0,887 & $6,3 \times 10$ \\
\hline \multicolumn{9}{|c|}{ Ferrítico AISI 444} \\
\hline $\mathrm{Ih}$ & 14,73 & $2,1 \times 10^{5}$ & 63,04 & 0,888 & - & - & - & $2,1 \times 10^{-}$ \\
\hline $4 \mathrm{~h}$ & 14,25 & $3.8 \times 10^{5}$ & 57,72 & 0,916 & - & - & - & $2,2 \times 10^{-}$ \\
\hline I dia & 14,04 & $1,1 \times 10^{6}$ & 48,19 & 0,918 & - & - & - & $3,2 \times 10^{-}$ \\
\hline 2 dias & 16,18 & $1,7 \times 10^{6}$ & 34,11 & 0,899 & - & - & - & $2,5 \times 10^{-}$ \\
\hline 7 dias & 15,04 & $2,4 \times 10^{6}$ & 29,83 & 0,903 & - & - & - & $3,6 \times 10^{-}$ \\
\hline 15 dias & 15,07 & $2,7 \times 10^{6}$ & 29,48 & 0,901 & - & - & - & $4,6 \times 10^{-}$ \\
\hline 30 dias & 15,82 & $1,0 \times 10^{6}$ & 29,00 & 0,876 & - & - & - & $4,7 \times 10^{-}$ \\
\hline \multicolumn{9}{|c|}{ Duplex UNS S32205 } \\
\hline $\mathrm{I} \mathrm{h}$ & 17,85 & $7,8 \times 10^{5}$ & 13,43 & 0,920 & - & - & - & $1,1 \times 10^{-}$ \\
\hline $4 \mathrm{~h}$ & 17,89 & $2,6 \times 10^{6}$ & 11,10 & 0,933 & - & - & - & $7,6 \times 10$ \\
\hline I dia & 17,55 & $8,8 \times 10^{6}$ & 9,56 & 0,935 & - & - & - & $1,4 \times 10^{-}$ \\
\hline 2 dias & 22,79 & $1,8 \times 10^{7}$ & 8,81 & 0,934 & - & - & - & $1,5 \times 10^{-}$ \\
\hline 7 dias & 20,11 & $1,8 \times 10^{7}$ & 9,82 & 0,915 & - & - & - & $2,1 \times 10^{-}$ \\
\hline 15 dias & 22,17 & $1,3 \times 10^{7}$ & 10,18 & 0,913 & - & - & - & $2,1 \times 10^{-}$ \\
\hline 30 dias & 19,78 & $1, I \times 10^{7}$ & 7,66 & 0,868 & - & - & - & $4,3 \times 10$ \\
\hline
\end{tabular}

$T$ (tempo), $R_{1}$ (resistência do eletrólito), $R_{2}$ (Resistência do filme passivo), $R_{3}$ (resistência à transferência de cargas para o aço martensítico e resistência da camada mais externa do filme passivo para o aço austenítico ), $\mathrm{Y}$ (capacitância), $\mathrm{n}$ (fator de fase constante), CPEI e CPE2 (elementos de fase constante), e X² (Parâmetro estatístico Chi-quadrado).

importante é a resistência à polarização $\left(R_{p}\right)$. Este parâmetro pode ser correlacionado diretamente a propriedade de barreira do filme passivo, indicando o quão resistente é a camada de óxido perante processos corrosivos. Os aços austenítico e duplex apresentaram os menores valores de $Y_{\text {CPEI }}$ em conjunto com valores elevados da $R_{p}$, na ordem de $10^{6} \Omega . \mathrm{cm}^{2}$ (austenítico) e $10^{7} \Omega . \mathrm{cm}^{2}$ (duplex), ou seja, filmes mais espessos e de elevada resistência à dissolução. Ademais, os valores de $Y_{\text {CPEI }}$ exibiram mínima oscilação ao longo do tempo, ou seja, houve mínima variação da espessura do filme durante os 30 dias de imersão em solução corrosiva. Este conjunto de resultados indica a formação de um filme de óxido de cromo estável e com propriedade de barreira frente à corrosão. $O$ aço ferrítico apresentou valores de $R_{p}$ pouco inferiores aos dos aços austenítico e duplex, porém na mesma magnitude de $10^{6} \Omega . \mathrm{cm}^{2}$. Além disso, exibiu valores de $Y$ até $485 \%$ maiores do que dos aços anteriores, indicando um filme de menor espessura. Isto pode ser causado pela ausência de $\mathrm{N}$, quando comparado aos aços austenítico e duplex, não havendo assim o mecanismo sinérgico entre Mo e $\mathrm{N}$ na interface metal solução do aço ferrítico $[8,9]$. Já o aço martensítico apresentou oscilações da resistência de polarização e capacitância devido ao baixo teor relativo de $\mathrm{Cr}(\mathrm{I}$ I,82\%). Em períodos longos de imersão, houve um decréscimo de $52,92 \%$ da $R_{p}$ e aumentos de até $49,40 \%$ da $\mathrm{Y}_{\mathrm{CPE}}$, indicando, em conjunto com as variações do ECA, a 
instabilidade da interface metal/solução e susceptibilidade à corrosão deste material. $\mathrm{O}$ aço martensítico ainda possui os menores valores de $R_{p}$ na ordem de $10^{5} \Omega . \mathrm{cm}^{2}$, conferindo assim, uma resistência à corrosão inferior quando comparado aos outros aços inoxidáveis em estudo.

\subsection{Resistência à Ruptura do Filme e Capacidade de Repassivação}

Os perfis voltamétricos apresentados na Figura 7 permitem analisar $\circ E_{p}$ e $E_{R}$ dos aços inoxidáveis através da varredura anódica e catódica. A principal região a ser analisada no voltamograma, é a faixa de potenciais em que a densidade de corrente se encontra próxima de zero, ou seja, mesmo o aço sendo polarizado, o filme de óxido resiste à corrosão evitando o fluxo de cargas. Desta forma, esta faixa de potenciais é avaliada até o potencial em que há o aumento brusco da densidade de corrente, caracterizando $\circ \mathrm{E}_{\mathrm{p}}$. Assim, quanto maior for $\circ \mathrm{E}_{\mathrm{p}}$, mais $\circ$ aço inoxidável resiste à polarização e consequentemente aos efeitos corrosivos, sendo este parâmetro obtido pelo perfil voltamétrico da Figura 7a [20]. Já o $E_{R}$ é obtido pela intersecção da varredura catódica com a anódica, sendo o potencial em que o material tornará a ter um fluxo de corrente nulo. Isto caracteriza a repassivação, em outras palavras, a reconstrução do filme de óxido de cromo, sendo o $E_{R}$ obtido no voltamograma da Figura $7 b$ [20]. Os valores do PREn, $E_{p}, E_{R}, R_{p}$ (30 dias de imersão) são apresentados na Tabela 3, em função dos principais elementos de liga que atuam na formação do filme de óxido de cromo e proteção à corrosão.

De acordo com os valores calculados do PREn, o aço austenítico deveria apresentar a maior resistência à corrosão localizada, seguido do aço duplex, ferrítico e por fim e mais suscetível à quebra do filme passivo, o aço martensítico. No entanto, estes resultados não estão completamente em concordância com os valores de $E_{p}$ e $R_{p}$ havendo discordância entre a resistência à corrosão localizada do aço austenítico e do aço duplex. Através da análise do potencial de pite e da resistência à polarização, o aço duplex apresenta um filme mais resistente à formação de pites. Esta aparente incoerência pode ser proveniente do valor do PREn levar em conta apenas a composição química dos aços inoxidáveis, desconsiderando a influência de variáveis metalúrgicas como tamanho de grão, interação entre fases e segregação de elementos de liga. Estudos recentes mostram que pode haver uma interação galvânica entre as fases $\alpha$ e $\gamma$, a qual potencializa o efeito dos elementos de liga na formação de um filme compacto de óxido de cromo $[9,14]$, podendo ser uma importante hipótese para a elevada resistência à polarização e potencial de pite do aço duplex (UNS S32205), mesmo possuindo PREn inferior ao do aço austenítico. Entretanto, de uma forma geral, estes dois aços apresentam as maiores resistências à corrosão em solução contendo íons cloreto, de acordo com seus valores de PREn, $E_{p}, E_{R}$ e $R_{p 30}$. Isto se deve pela presença de elevados teores de Mo no aço
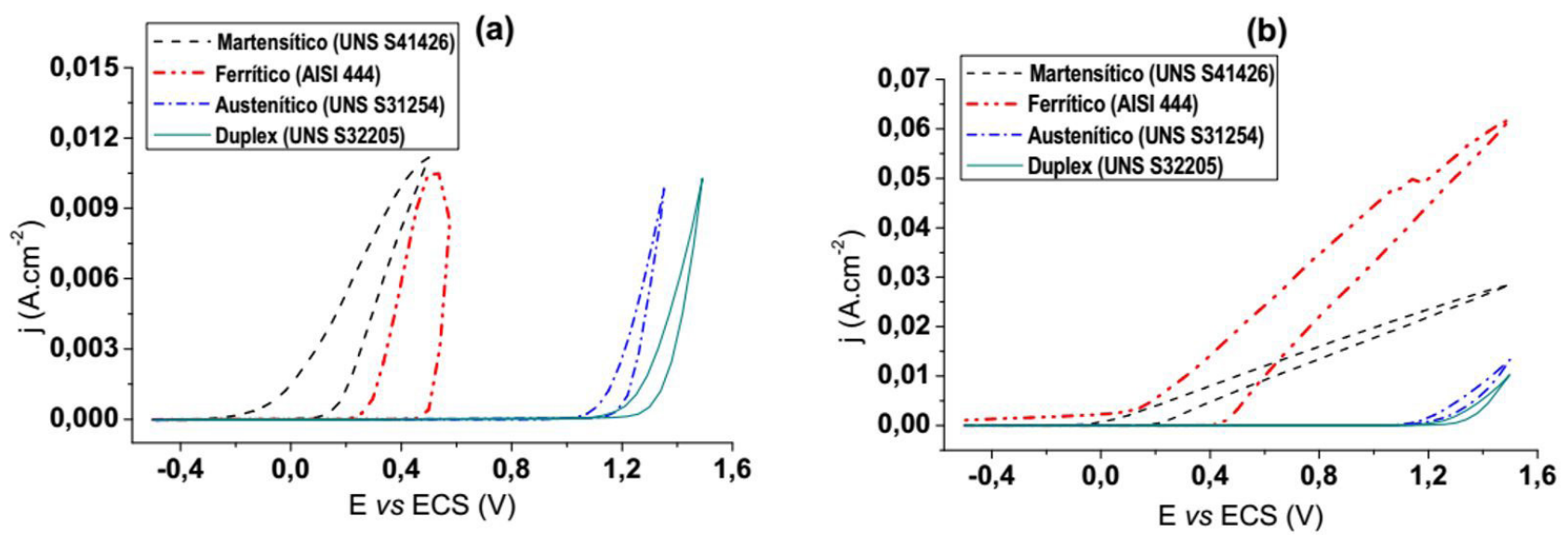

Figura 7. Voltamogramas dos aços martensítico (UNS S4I426), ferrítico (AISI 444), austenítico (UNS S3I254) e duplex (UNS S32205) em solução de $3,5 \% \mathrm{NaCl}$, com $\mathrm{E}_{\mathrm{I}}$ igual a $-500 \mathrm{mV}$. $\mathrm{E}_{\mathrm{F}}$ (a) igual ao potencial em que a densidade de corrente atinge $10 \boldsymbol{m ~ A . c m ~}^{-2}$ e $\mathrm{E}_{\mathrm{F}}$ (b) igual a $1500 \mathrm{mV}$, ambos sob uma velocidade de varredura de $5 \mathrm{mV} / \mathrm{s}$.

Tabela 3. Correlação entre a composição química e os potenciais de quebra $\left(E_{B}\right)$, repassivação $\left(E_{R}\right)$, resistência à polarização $\left(R_{P 30}\right)$ após 30 dias de imersão em solução de 3,5\% NaCl e o PREn dos aços ferrítico (AISI 444), martensítico (UNS S4I426), austenítico (UNS S3 I 254 ) e duplex (UNS S32205)

\begin{tabular}{cccccccc}
\hline Aço & PREn & $\mathbf{E}_{\mathbf{p}}(\mathbf{m V})$ & $\mathbf{E}_{\mathbf{R}}(\mathbf{m V})$ & $\mathbf{R}_{\mathbf{P} 30}\left(\Omega . \mathbf{c m}^{2}\right)$ & $\% \mathbf{C r}$ & $\% \mathbf{M o}$ & $\% \mathbf{N i}$ \\
\hline UNS S4I426 & 18,73 & 100,2 & $-19,9$ & $1,5 \times 10^{5}$ & 11,8 & 2,1 & 5,8 \\
AISI 444 & 26,05 & 459,8 & $-219,9$ & $1,0 \times 10^{6}$ & 17,8 & 2,5 & 0,3 \\
UNS S3I254 & 44,57 & 1099,5 & 1019,5 & $3,6 \times 10^{6}$ & 18,6 & 6,9 & 17,9 \\
UNS S32205 & 36,92 & 1219,4 & 1139,3 & $1,1 \times 10^{7}$ & 22,5 & 3,4 & 5,3 \\
\hline
\end{tabular}




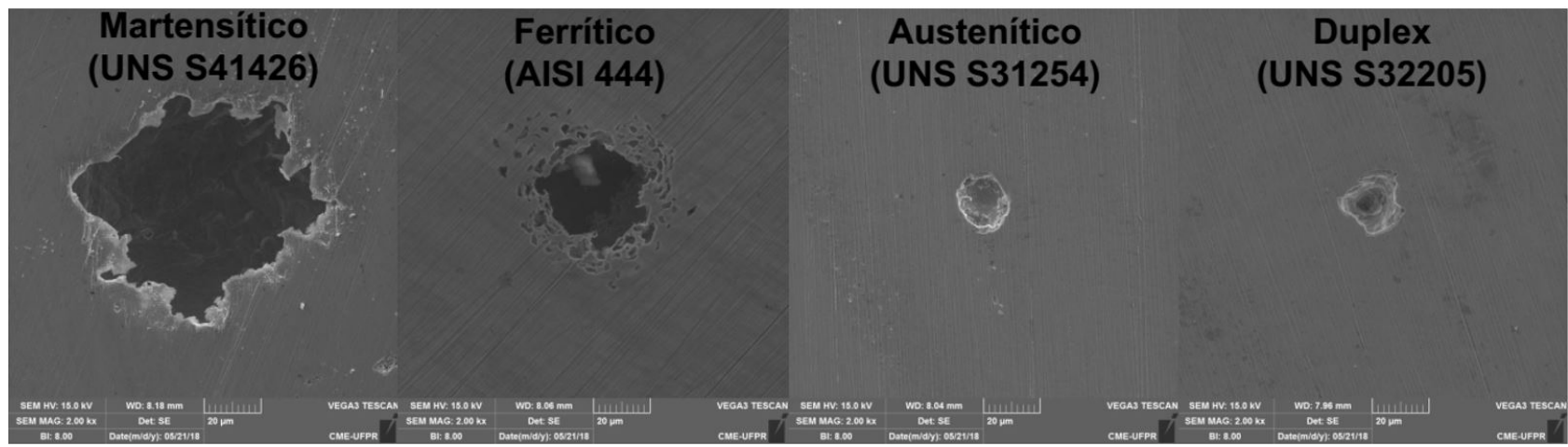

Figura 8. Imagens de MEV com ampliação de 2000x dos aços martensítico (UNS S4I426), ferrítico (AISI 444), austenítico (UNS S3 I254) e duplex (UNS S32205) após ensaio de voltametria cíclica.

duplex e austenítico (3,4\% e 6,9\% respectivamente), em conjunto com aproximadamente $0,2 \%$ de $\mathrm{N}$ existente nessas ligas $[7,8]$. O elemento molibdênio atua na desprotonação de hidróxidos que enriquecem a interface metal/filme com oxigênio, facilitando a formação de óxido de cromo $[7,8]$. Além disso, o elemento nitrogênio atua na formação de amônio e amônia que aumentam o pH do ambiente facilitando a formação de molibdatos [7,8]. A formação destes molibdatos como $\circ \mathrm{MoO}_{4}^{2-}$, assim como oxiânions provenientes do nitrogênio $\left(\mathrm{NO}_{\times}^{-}\right)$, repelem eletrostaticamente íons cloreto $\left(\mathrm{Cl}^{-}\right)$, ou seja, aumentam o $\mathrm{E}_{\mathrm{p}}$ e os valores de $\mathrm{R}_{\mathrm{p}}$ pela propriedade cátion-seletiva da camada externa do filme de $\mathrm{Cr}_{2} \mathrm{O}_{3}[7,8]$. Na repassivação do filme, estes compostos aumentam o $\mathrm{pH}$ dentro do pite, reduzindo os efeitos corrosivos e facilitando a formação do óxido de cromo, além de atuarem como barreira físico-química à entrada de íons corrosivos, elevando o valor do $E_{R}$ dos aços duplex e austenítico $[7,8]$.

A menor estabilidade da interface metal/solução e potencial de pite do aço ferrítico com relação ao austenítico podem ser função da ausência de $\mathrm{N}$. Isto se deve a tendência de haver uma redução do $\mathrm{pH}$ da solução ao longo do tempo de imersão, em conjunto com a necessidade de um ambiente neutro ou alcalino para formação de molibdatos, requisito que é atendido pela formação de amônia e amônio através da presença do $\mathrm{N}$. A magnitude do $\mathrm{E}_{\mathrm{R}}$ do aço ferrítico, cerca de 91\% inferior ao do martensítico, pode estar correlacionado a ausência de $\mathrm{Ni}$, que atua na repassivação, sendo corroído preferencialmente ao substrato metálico. $O$ teor de níquel pode também explicar a elevada estabilidade eletroquímica do aço austenítico, contendo em torno de $17,9 \%$ deste elemento [6-8].

As imagens reveladas por MEV, após a varredura de potenciais em meio agressivo contendo cloretos, são exibidas na Figura 8. Os aços martensítico e ferrítico, possuíram os maiores pites, tanto em quantidade como em dimensão. Já os aços austenítico e duplex, contendo a sinergia entre $\mathrm{Cr}-\mathrm{Mo}-\mathrm{N}$, possuem menos e menores pites, corroborando com os dados obtidos por VC e EIE. Assim, os aços austenítico e duplex apresentam resistência à corrosão localizada superior quando comparado aos demais aços inoxidáveis em estudo, corroborando com os valores de PREn, $E_{p}$ e $R_{p}$.

\section{CONCLUSÕES}

O estudo comparativo entre aços inoxidáveis de diferentes classes permite o conhecimento e desenvolvimento de ligas cada vez mais resistentes à corrosão. Por técnicas eletroquímicas especíícas, os aços ferrítico (AISI 444), austenítico (UNS S3 I 254) e duplex (UNS S32205) apresentaram filmes estáveis de $\mathrm{Cr}_{2} \mathrm{O}_{3}$ do tipo barreira, ao longo de 30 dias de imersão em meio agressivo contendo cloretos, enquanto o aço martensítico (UNS S4 I 426) se apresentou instável devido ao seu baixo teor relativo de $\mathrm{Cr}$ ( $11,8 \%)$. Já os aços duplex (UNS S32205) e austenítico (UNS S3 I254) apresentaram excelente resistência à corrosão por pites quando comparados aos aços ferrítico (AISI 444) e martensítico (UNS S4I426). O maior teor de $\mathrm{Cr}$ aumenta de forma expressiva a resistência e estabilidade do filme passivo de $\mathrm{Cr}_{2} \mathrm{O}_{3}$, além da coexistência de $\mathrm{Cr}-\mathrm{Mo}-\mathrm{N}$ como elementos de liga promoverem mecanismos que melhoram a propriedade de barreira do filme passivo dos aços inoxidáveis. Por fim, conclui-se que aços inoxidáveis ferríticos e duplex podem possuir resistência à corrosão semelhante e até superior do que um aço inoxidável austenítico (UNS S3 I 254), podendo ser potenciais substitutos aos aços inoxidáveis austeníticos comerciais, como o AISI 304 e AISI 3 I6.

\section{Agradecimentos}

Os autores agradecem às agências de fomento Capes e CNPq e aos laboratórios e grupos de pesquisa: Grupo de Biomateriais e Eletroquímica (GBio - UFPR), Centro de Microscopia Eletrônica (CME - UFPR), Laboratório de Óptica de raios X e Instrumentação (LORXI - UFPR), e ao Laboratório de Corrosão e Eletroquímica do Instituto LACTEC. 


\section{REFERÊNCIAS}

I Koch G, Brongers M, Thompson N, Virmani Y, Payer J. Corrosion costs and preventive strategies in the United States, FHWA-RD-0I-156. Houston: US Department of Transportation, Federal Highway Administration (FHWA); 2001 .

2 Groysman A. Corrosion problems and solutions in oil refining and petrochemical industry. 32nd ed. Cham: Springer; 2017. $351 \mathrm{p}$.

3 Brondel D, Edwards R, Hayman A, Hill D, Semerad T. Corrosion in the oil industry. Oilfield Review. 1994;6(2):4-69.

4 Davison M, DeBold T, Johnson M. Corrosion of stainless steels. In: American Society for Metals. Metals handbook. I0th ed. Materials Park: ASM; 199I. p. I325-I38I. (vol. I3).

5 Jinlong L, Tongxiang L, Chen W, Limin D. Comparison of corrosion properties of passive films formed on coarse grained and ultra fine grained AISI 2205 duplex stainless steels. Journal of Electroanalytical Chemistry. 20I5;757:263269.

6 Fattah-Alhosseini A, Vafaeian S. Comparison of electrochemical behavior between coarse-grained and fine-grained AISI 430 ferritic stainless steel by Mott-Schottky analysis and EIS measurements. Journal of Alloys and Compounds. 2015;639:30I-307.

7 Olsson A. The influence of nitrogen and molybdenum on passive films formed on the austeno-ferritic stainless stell 2205 studied by AES and XPS. Corrosion Science. 1995;37(3):467-479.

8 Loable C, Viçosa IN, Mesquita TJ, Mantel M, Nogueira RP, Berthomé G, et al. Synergy between molybdenum and nitrogen on the pitting corrosion and passive film resistance of austenitic stainless steels as a $\mathrm{pH}$-dependent effect. Materials Chemistry and Physics. 2017;186:237-245.

9 Cheng X, Wang Y, Li X, Dong C. Interaction between austein-ferrite phases on passive performance of 2205 duplex stainless steel. Journal of Materials Science and Technology. 2018;34(II):2I40-2I48.

10 Vicente AA, Cabral DA, Espinosa DCR, Tenório J A S. Efeito dos gases de proteção na microestrutura e nas cinéticas de oxidação a altas temperaturas ao ar de juntas soldadas de um aço inoxidável austenítico através do processo MIG/MAG. Tecnologica em Metalurgia, Materiais e Mineração. 2017;14(4):357-365.

I I Vicente AA, Cabral DA, Coleti JL, Telles VB, Santos T F A, Tenório J A S. Caracterização microestrutural e análises químicas semi-quantitativas das fases ferrita e austenita em aços inoxidáveis duplex. In: Anais do $72^{\circ}$ Congresso Anual da ABM; 2017; São Paulo. São Paulo: ABM; 2017.

12 Yamamoto Y, Brady MP, Lu ZP, Maziasz PJ, Liu CT, Pint BA, et al. Creep-resistant Al2O3 austenitic stainless steels. Science. 2007;316:433-436.

13 Sabioni ACS, Huntz AM, Luz EC, Mantel M, Haut C. Comparative study of high temperature oxidation behaviour in AISI 304 and AISI 439 stainless steels. Materials Research. 2003;6(2): I79-I85.

14 Cheng X, Wang Y, Dong C, Li X. The beneficial galvanic effect of the constituent phases in 2205 duplex stainless steel on the passive films formed in a $3.5 \% \mathrm{NaCl}$ solution. Corrosion Science. 2018;134:122-130.

15 Jiang Y, Sun T, Li J, Xu J. Evaluation of pitting behavior on solution treated duplex stainless steel UNS S3 I 803. Journal of Materials Science and Technology. 2014;30(2): 179-183.

16 Bird CR. Stainless steel casting alloys: metallographic techniques and microstructures. In: American Society for Metals. Metals handbook. I0th ed. Materials Park: ASM; 199I. p. I325-138I. (vol. 9).

17 Carmezim MJ, Simões AM, Montemor MF, Belo MC. Capacitance behavior of passive films on ferritic and austenitic stainless steel. Corrosion Science. 2005;47(3):58I-59I.

18 Hakiki NE, Boudin S, Rondot B, Belo MC. The electronic structure of passive films formed on stainless steels. Corrosion Science. 1995;37(1 I): 1822-1837.

19 Marcelin S, Pébère N, Régnier S. Electrochemical characterisation of a martensitic stainless steel in a neutral chloride solution. Electrochimica Acta. 2013;87:32-40.

20 Fonseca I, Proença L, Capelo S. A voltametria cíclica e de varrimento linear unidirecional: suas potencialidades na caracterização de processos de corrosão. Corrosão e Protecção de Materiais. 2015;34(I):I2-2I.

Recebido em: 7 Set. 2019

Aceito em: 20 Jan. 2020 